\title{
Role of free school lunch in the associations between family-environmental factors and children's fruit and vegetable intake in four European countries
}

\author{
Carola Ray 1,2,*,Eva Roos ${ }^{1,2}$, Johannes Brug ${ }^{3}$, Isabel Behrendt ${ }^{4}$, Bettina Ehrenblad ${ }^{5}$, \\ Agneta Yngve ${ }^{6}$ and Saskia J te Velde ${ }^{3}$ \\ ${ }^{1}$ Folkhälsan Research Center, Paasikivenkatu 4, 00250 Helsinki, Finland: ${ }^{2} \mathrm{Hielt}$ Institute, Department of Public \\ Health, University of Helsinki, Helsinki, Finland: ${ }^{3} E M G O$ Institute for Health and Care Research and Department \\ of Epidemiology \& Biostatistics, VU University Medical Center, Amsterdam, the Netherlands: ${ }^{4}$ Institute for \\ Nutritional Sciences, Justus-Liebig-University of Giessen, Giessen, Germany: ${ }^{5}$ Unit for Public Health Nutrition, \\ Department for Biosciences and Nutrition at Novum, Karolinska Institutet, Stockholm, Sweden: ${ }^{6}$ Department of \\ Health, Nutrition and Management, Oslo and Akershus University College, Lilleström, Norway
}

Submitted 9 November 2011: Final revision received 25 June 2012: Accepted 3 July 2012: First published online 14 September 2012

\begin{abstract}
Objective: To determine whether an association exists between different clusters of fruit- and vegetable-specific family-environmental factors and children's daily fruit and vegetable intake, and whether these associations differ between countries with different school lunch policies.

Design: Cross-sectional data from four European countries participating in the Pro Greens project in 2009. These countries have different school food policies: two serve free school lunches and two do not. Self-administered data were used. Food frequency questions served to assess fruit and vegetable intakes. The study assessed sixteen children-perceived family-environmental factors, which were clustered based on principal component analysis into five sum variables: fruit and vegetable encouragement; vegetable modelling, family routine and demand; fruit modelling; fruit and vegetable snacking practices; and fruit and vegetable allowing.

Setting: Schools in Finland, Germany, Sweden and the Netherlands.

Subjects: Schoolchildren aged 11 years ( $n$ 3317).

Results: Multilevel logistic regression analyses revealed positive associations between nearly all clustered family-environmental factors and daily fruit and vegetable intake. The study tested a moderation effect between family-environmental factors and school lunch policy. In five out of twenty models significant interactions occurred. In the stratified analyses, most of the associations between family-environmental factors and raw and cooked vegetable intake were stronger in Germany and the Netherlands, neither of which provided free school lunches.

Conclusions: Children reporting more fruit- and vegetable-promoting familyenvironmental factors had a more frequent intake of fruits and vegetables; the associations were stronger for vegetable intakes in countries providing no free school lunches, suggesting that parental involvement is crucial when schools offer no vegetables.
\end{abstract}

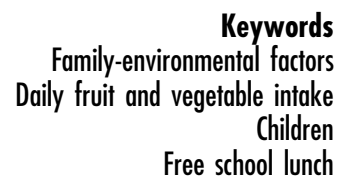

Ample fruit and vegetable intake is considered an important part of a healthy diet ${ }^{(1-3)}$. Children's consumption of fruits and vegetables is generally much lower than what health authorities recommend ${ }^{(4)}$, and since adolescent fruit and vegetable intake tends to track into adulthood $^{(5,6)}$, improving fruit and vegetable intake among schoolchildren and adolescents is important. To guide interventions promoting fruits and vegetables, more knowledge is needed about potential changeable determinants and mediating variables that can be targeted in future intervention strategies. Research and behavioural theory suggest that potentially important determinants and mediators can be found in the family and home environment $^{(7)}$. In Davison and Birch's ecological model, for example, parenting style and family characteristics determine children's health behaviours ${ }^{(8)}$.

Parenting practices are defined as practices related to specific behaviours through which parents perform their parental duties ${ }^{(9)}$. Through parenting practices, parents aim to socialise their children. The practices are situation and 
context dependent, and several studies have found that food-related parenting practices associate with children's daily intakes of fruits and vegetables ${ }^{(10-14)}$, but the evidence for different, more specific aspects of food-related parenting practices is mixed ${ }^{(15)}$. Research has found that more obligatory rules, such as parents obliging their children to eat vegetables and requiring their children to taste the vegetables they have prepared, correlate positively with children's vegetable intake ${ }^{(15)}$, whereas verbal parental encouragement to eat fruits and vegetables has shown no clear association with fruit and vegetable intake ${ }^{(13,16)}$. Obtaining an overview of the associations between parenting practices and children's fruit and vegetable intake is challenging, since various studies have operationalised the concept of parenting practices differently. The present study therefore focuses on parenting practices as well as on other family-environmental factors associated with children's fruit and vegetable intake, such as parental modelling and facilitation (i.e. parents cutting up fruits or vegetables as a snack). Previous studies have found positive correlations between parents' fruit and vegetable intakes, parental modelling and those of their children ${ }^{(10,13,17-21)}$. However, the fact that previous studies have used different methods to assess parents' and/or children's intake has complicated interpretations of the results. Although most of the studies separately assessed parents' and children's intake levels, some studies used child reports to assess parents' intake $\mathrm{e}^{(13,15,17,21)}$. One study assessed only mothers' and their daughters' intake, which correlated positively ${ }^{(17)}$. Additionally, eating dinner together can provide parents the opportunity to actively serve as a parental role model, and eating together has been associated with children's fruit and vegetable intake ${ }^{(17,22-25)}$.

Another reason for the mixed findings on the association between family-environmental factors and fruit and vegetable intake could be that different factors influence intake levels due to cross-country differences in food culture and practices ${ }^{(11,21,26)}$. Many differences in such practices, such as how vegetables are prepared and the context in which they are eaten, exist in European countries, which may influence family-environmental factors; alternatively, family-environmental factors may affect intake differently depending on the same nationally or culturally appropriate practices. One such country difference in food practices that may be of crucial importance is school meal practices. Finland and Sweden, two Nordic countries which are geographically and historically close to each other, not only share similar food cultures, but also have similar school lunch programmes. Both countries serve a free hot meal that complies with nutritional recommendations for lunch every school day in all schools ${ }^{(27,28)}$. The school lunch is a part of the curriculum in both countries and all pupils must participate in the meal, which is served with vegetables; neither country serves fruit on a daily basis in schools. Most other European countries provide no obligatory cooked school lunch, although the food culture in Northern Europe is closer to the food culture of the Nordic countries. The food cultures in the Netherlands and Germany are generally quite similar, and their school lunch systems have much in common. In the Netherlands, many children go home to eat lunch or bring their own lunch from home, which typically consists of sandwiches; purchasing food at school is not an option. Nor does Germany provide free lunches, although it is usually possible to purchase food at school; the assortment of food available in the school canteens varies between schools and may constitute a full meal that includes vegetables, fast food, salads and more. German children may also bring food from home for lunch, and some go home for lunch.

Differences in school lunch practices and opportunities may not only influence children's fruit and vegetable intakes, but may also modify the associations of familyenvironmental factors with children's fruit and vegetable consumption. That is, for children who must eat a school lunch that includes vegetables, parental influences may be less crucial, since the vegetables in the school lunch will be part of the children's daily intakes regardless of family-environmental factors. However, the potential moderating effect of providing school lunches on familyenvironmental factors, namely the intake relationship, remains unexplored.

Therefore, the current study first aims to explore the association between family-environmental factors and children's fruit and vegetable intakes across four countries in Europe: Finland, Germany, Sweden and the Netherlands. Second, the study aims to determine whether such associations differ between countries with different schoolbased food practices, namely those that provide a free lunch with vegetables (Sweden, Finland) and those that do not (Germany, the Netherlands). The hypothesis predicts that fruit- and vegetable-specific family-environmental factors are significantly positively associated with children's intakes and that these associations are stronger in the two countries where children receive no free school lunches.

\section{Methods}

\section{Procedure}

The Pro Greens study was conducted in ten European countries in 2009 among a total of 8736 children. The present study uses a sub-sample consisting of data from two countries (Finland and Sweden) that offer free school lunches and data from two countries that offer no lunch at school (Germany, the Netherlands). All four countries' foods cultures resemble each other, and their fruit and vegetable intakes are somewhat similar ${ }^{(4,29)}$. Schools in Finland, Germany and Sweden were recruited regionally, whereas schools in the Netherlands were recruited 
nationwide ${ }^{(30)}$. All participating schools received a letter or a telephone call introducing the project and enquiring about participation. In Finland, all nineteen schools invited to participate accepted (participation rate 100\%); in Sweden, twenty-seven of sixty participated (45\%); and in Germany, fourteen out of forty-five (31\%). In the Netherlands, fifty-three of the 414 schools sampled initially agreed to participate (13\%), but only forty-five schools actually participated due to practical reasons such as logistical and time constraints. The procedure for collecting data has been performed before and entailed sending letters to teachers ${ }^{(31,32)}$. The letters included questionnaires with instructions to the teachers about how to collect the data. The children completed their questionnaire during a lesson and took a questionnaire home for one of their parents to complete. The teachers returned all the questionnaires in closed envelopes to the national study groups, who in turn input the data into a database according to an agreed data protocol.

\section{Participants}

Most of the children recruited were born in 1998 and turned 11 years old in 2009. Due to practical reasons and differences in educational systems, about half of the children recruited in Finland turned 12 years old in 2009. In Finland, 934 of the 1123 children invited agreed to participate; the response rate was $83 \cdot 2 \%$. The Finnish children attended a Swedish-speaking school on the south or west coast of Finland. The sample was socioeconomically representative of the area. In Germany, 816 children agreed to participate (response rate $62 \cdot 8 \%$ ). The German children lived in the state of Hesse, attended a public school and were of lower socio-economic status than the general German population. In the Netherlands, 589 children participated in the study (response rate $56.3 \%$ ). The Dutch children were recruited from schools randomly selected from a list of all schools in the Netherlands. The participating schools represented different regions of the Netherlands, and the proportion of mothers with a high level of education was similar to that of the general Dutch population. For this reason, the Dutch sample was considered representative of the Dutch population. In Sweden, 841 children participated in the study (response rate $68 \cdot 2 \%)$. The Swedish children lived in the Stockholm area and the sample was socio-economically representative of the Stockholm region.

All relevant medical ethics committees in each participating country approved the Pro Greens study protocol in the autumn of 2008. In Finland: the Ethical Committee of the Department of Public Health of University of Helsinki; in Germany: the Ethical Committee of the Medical Faculty of the Justus-Liebig-University Giessen; in the Netherlands: the Medical Ethics Committee of the VU University Medical Center, Amsterdam; in Sweden: the Regional Board of the Ethical Review Board at the Karolinska Institute in Stockholm.
All parents and their children agreed to participate by signing a consent form.

\section{Measures}

\section{Fruit and vegetable intake}

Fruit and vegetable intakes were assessed using the food frequency questions developed in the Pro Children study $^{(31,32)}$. Daily fruit and vegetable intake was enquired as follows with four separate questions: 'How often do you usually eat: 1 . fresh fruits, 2 . salads or grated vegetables, 3. raw vegetables or 4. cooked vegetables?' Answer options ranged over an eight-point scale ('never', 'less than 1 d/week', ' 1 d/week', '2-4d/week', '5-6d/week', 'every day, once daily', 'every day, twice daily' and 'every day, more than twice daily'). The food frequency questions proved to be fairly accurate in ranking children's fruit and vegetable intake ${ }^{(33)}$. The children's intake variables of fruits, salads and grated vegetables, raw vegetables and cooked vegetables were all separately dichotomised to 'not daily' and 'daily' intake. The variables were not normally distributed, so it was methodologically more correct to dichotomise the fruit and vegetable variables. Also, this solution was chosen for practical reasons: each country's recommendations for fruit and vegetable intake differed and these variables included each country's recommendations. Using dichotomous variables also made it easier to interpret the results and to compare them with those of previous studies.

\section{Family-environmental factors}

Family-environmental factors as the children perceived them were assessed with questionnaire items devel oped for the Pro Children study ${ }^{(34)}$. The sixteen familyenvironmental factors included items about parental modelling, parental encouragement, family routine, family rules and parental facilitation (Table 1). The Pro Children study had already tested the reliability and validity of the questionnaire items on 10- to 11-year-old children. The Pro Children questionnaire seemed reliable and valid in assessing determinants for children's fruit and vegetable intake ${ }^{(34)}$.

\section{Confounders}

Children's gender and age were included in the analyses as possible confounders. Children reported their gender as well as the month and year in which they were born. Each country provided data on the month and year in which the data were collected, which served as the basis for calculating the children's ages. The parental questionnaire enquired about the child's mother's highest level of education; this information was then transferred to a dichotomous variable, thereby distinguishing children with mothers who reported holding a high school, a bachelor's or a master's degree from those with mothers with lower levels of education. 
Table 1 Perceived family-environmental items and their rotated factor loadings in the rotated component matrix $(n$ 2913), Pro Greens project, 2009

\begin{tabular}{|c|c|c|c|c|c|}
\hline \multirow[b]{2}{*}{ Item } & \multicolumn{5}{|c|}{ Rotated factor loadings } \\
\hline & $\begin{array}{c}\text { FV } \\
\text { encouragement }\end{array}$ & $\begin{array}{l}\mathrm{V} \text { modelling, family } \\
\text { routine, and demand }\end{array}$ & $\begin{array}{c}\mathrm{F} \\
\text { modelling }\end{array}$ & $\begin{array}{l}\text { FV snacking } \\
\text { practices }\end{array}$ & $\begin{array}{l}\text { FV } \\
\text { allowing }\end{array}$ \\
\hline My mother eats fruit every day & & & 0.73 & & \\
\hline My father eats fruit every day & $0 \cdot 21$ & & $0 \cdot 80$ & & \\
\hline My mother eats vegetables every day & & 0.77 & $0 \cdot 37$ & & \\
\hline My father eats vegetables every day & & 0.71 & 0.45 & & \\
\hline My mother encourages me to eat fruit every day & 0.80 & & 0.23 & & \\
\hline My father encourages me to eat fruit every day & 0.78 & & 0.33 & & \\
\hline $\begin{array}{l}\text { My mother encourages me to eat vegetables } \\
\text { every day }\end{array}$ & 0.72 & 0.50 & & & \\
\hline $\begin{array}{l}\text { My father encourages me to eat vegetables } \\
\text { every day }\end{array}$ & 0.73 & 0.45 & & & \\
\hline I often eat fruit with my family & $0 \cdot 28$ & & 0.35 & 0.58 & \\
\hline I often eat vegetables together with my family & & 0.61 & & 0.38 & \\
\hline $\begin{array}{l}\text { Do your parents demand that you eat fruit } \\
\text { every day? }\end{array}$ & 0.55 & & & $0 \cdot 30$ & \\
\hline $\begin{array}{l}\text { Do your parents demand that you eat vegetables } \\
\text { every day? }\end{array}$ & $0 \cdot 41$ & 0.63 & & & \\
\hline Are you allowed to eat as much fruit as you like? & & & & & 0.83 \\
\hline $\begin{array}{l}\text { Are you allowed to eat as many vegetables as } \\
\text { you like? }\end{array}$ & & & & & 0.83 \\
\hline $\begin{array}{l}\text { Does your mother or father usually cut up fruit } \\
\text { for you as a snack? }\end{array}$ & & & & $0 \cdot 80$ & \\
\hline $\begin{array}{l}\text { Does your mother or father usually cut up } \\
\text { vegetables } \\
\text { for you as a snack? }\end{array}$ & & & & $0 \cdot 71$ & $0 \cdot 21$ \\
\hline Cronbach's $\alpha$ & $0 \cdot 83$ & 0.72 & 0.57 & 0.63 & 0.63 \\
\hline
\end{tabular}

Extraction method: principal component analysis; rotation method: varimax.

Answer options for the first ten questions: 'I fully agree', 'I agree', 'I neither agree nor disagree', 'I disagree' and 'I don't have or don't see my mother/father'. Answer options for the last six questions: 'yes, every day', 'yes, most days', 'sometimes', 'seldom' and 'never'.

A bold value indicates that the item is included in the index.

\section{Statistical analyses}

Descriptive statistics, such as means and proportions, served to describe the main variables. Medians and interquartile ranges (25th percentile-75th percentile, $\mathrm{P}_{25}-\mathrm{P}_{75}$ ) were used for skewed data. Variance analysis was used to test differences in mean age between country and gender, and the $\chi^{2}$ test was used to test differences in daily fruit and vegetable intake between country and gender. The Kruskall-Wallis $U$ test and the Mann-Whitney $U$ test were used to test differences by country and gender for skewed variables (e.g. family-environmental factors).

To group family-environmental factors, a principal component analysis was conducted and five dimensions with eigenvalues exceeding 1 were found (Table 1). Based on the eigenvalues, five indices were defined, including all practices that scored over 0.5 in the rotated component matrix (varimax). New scores for the five indices were formed by summing up the answer options (range 1-5); thereafter, the new scores were divided by the number of variables included in that particular index. Based on the content of the indices, the five dimensions were as follows: (i) fruit and vegetable encouragement (FV encouragement); (ii) vegetable modelling, family routine and demand to eat vegetables (V modelling, family routine and demand); (iii) fruit modelling ( $\mathrm{F}$ modelling); (iv) facilitation of fruit and vegetable eating and fruit family routine (FV snacking practices); and (v) allowing the child to eat fruits and vegetables (FV allowing; see Table 1).

Logistic multilevel regression analysis served to test the association between the sum variables of the five independent family-environmental factors and the dependent daily fruit and vegetable intake variables in the whole sample. Multilevel analyses were conducted to take into account the fact that children were clustered within schools $^{(35)}$. All analyses were adjusted for the gender and age of the child, the mother's highest level of education and the school lunch policy group.

To test whether the school lunch policy group, i.e. the distinction between countries that do (Sweden, Finland) or do not (Germany, the Netherlands) provide school lunches that contain vegetables, modified the associations between family-environmental factors and intakes, further analyses included interaction terms (familyenvironmental factor $\times$ school lunch policy group). If interaction terms approached significance $(P$ value $<0 \cdot 1)$, stratified analyses by school lunch policy group followed. Results from the multilevel logistic regression analyses were reported as odd ratios and $95 \%$ confidence intervals.

The analyses were performed using the statistical software packages PASW Statistics 18.0 (2010) and MLwiN version $2 \cdot 22^{(36)}$. 


\section{Results}

\section{Sample characteristics}

The mean age in the study population was 11.4 years, varying between 11.3 and 11.6 years in the four countries (Table 2). The proportions of highly educated mothers were higher in Sweden and Finland, with about half of the mothers in the more highly educated group, than in the Netherlands and Germany.

\section{Intake levels}

Some differences in daily fruit intakes were observed between the countries, with German children reporting the highest and Finnish children the lowest proportion of daily fruit intake (Table 2). Further differences were found in vegetable intakes, with Finnish children reporting the most frequent intake of salads, Swedish children being the most likely to report daily raw vegetable intake and Dutch children being the most likely to report eating cooked vegetables daily.

\section{Family-environmental factors}

FV encouragement was reportedly lower in Finland than in the other countries (Table 2). Dutch children reported more V modelling, family routine and demand, whereas $\mathrm{F}$ modelling was lowest in Sweden and Finland; FV snacking practices were more common among children in the Netherlands. FV allowing was high in all countries, but the lowest in the Netherlands.

\section{Associations between family-environmental factors and fruit and vegetable intake}

In the total sample, nearly all family-environmental factors showed a significant positive association with fruit and vegetable outcomes (Table 3 ). The only exceptions were the two associations between FV allowing and daily fruit intake and daily cooked vegetable intake.

\section{Interactions and stratified analyses}

Of the twenty interactions tested, five suggested a possibly significant modification (Table 3). Stratified analyses revealed stronger associations between familyenvironmental factors and intake levels in the group of Dutch and German children (Table 4). Only the association between $\mathrm{V}$ modelling, family routine and demand and intake of raw vegetables was stronger in the group of Finnish and Swedish children.

Table 2 Description of the population studied and variables used, Pro Greens project, 2009

\begin{tabular}{|c|c|c|c|c|c|c|c|}
\hline & The Netherlands & Germany & Sweden & Finland & Total & Girls & Boys \\
\hline Number of children & 577 & 783 & 726 & 934 & 3020 & 1485 & 1535 \\
\hline Mean age (years)† & $11 \cdot 28$ & $11 \cdot 53$ & $11 \cdot 25$ & $11 \cdot 37$ & $11 \cdot 37^{\star \star \star}$ & $11 \cdot 34$ & $11 \cdot 40^{\star \star *}$ \\
\hline $\begin{array}{l}\text { Mother's education (high education, \%)‡ } \\
\text { Fruit intake }\end{array}$ & $29 \cdot 80$ & $18 \cdot 10$ & $57 \cdot 90$ & $48 \cdot 80$ & $40 \cdot 50^{\star \star \star}$ & $49 \cdot 30$ & $50 \cdot 70$ \\
\hline$n$ & 575 & 764 & 719 & 881 & 2937 & 1447 & 1490 \\
\hline At least once daily (\%)‡ & $48 \cdot 5$ & $49 \cdot 9$ & $39 \cdot 8$ & $33 \cdot 0$ & $42 \cdot 0^{\star \star \star}$ & $47 \cdot 0$ & $37 \cdot 2^{\star \star \star}$ \\
\hline \multicolumn{8}{|l|}{ Salad/grated vegetables intake } \\
\hline$n$ & 573 & 762 & 710 & 880 & 2923 & 1440 & 1483 \\
\hline At least once daily (\%)‡ & $9 \cdot 2$ & $15 \cdot 4$ & $33 \cdot 4$ & $39 \cdot 2$ & $25 \cdot 7^{\star \star \star}$ & $31 \cdot 3$ & $20 \cdot 4^{\star \star \star}$ \\
\hline \multicolumn{8}{|l|}{ Raw vegetables intake } \\
\hline$n$ & 570 & 755 & 694 & 878 & 2895 & 1427 & 1468 \\
\hline At least once daily (\%)‡ & $7 \cdot 4$ & $14 \cdot 4$ & $20 \cdot 5$ & $16 \cdot 3$ & $15 \cdot 1^{\star \star \star}$ & $19 \cdot 1$ & $11 \cdot 2^{\star \star \star}$ \\
\hline \multicolumn{8}{|l|}{ Cooked vegetables intake } \\
\hline$n$ & 572 & 766 & 712 & 877 & 2925 & 1440 & 1485 \\
\hline At least once daily (\%)‡ & 18 & $3 \cdot 8$ & $1 \cdot 7$ & $2 \cdot 7$ & $5 \cdot 7^{\star \star \star}$ & $6 \cdot 7$ & $4 \cdot 8^{*}$ \\
\hline \multicolumn{8}{|l|}{ Family-environmental factors (range 1-5) } \\
\hline \multicolumn{8}{|l|}{ FV encouragement } \\
\hline Median§, $\|$ & $3 \cdot 60$ & $3 \cdot 80$ & $3 \cdot 60$ & $3 \cdot 20$ & $3 \cdot 40^{\star \star \star}$ & $3 \cdot 60$ & $3 \cdot 40$ \\
\hline $\begin{array}{l}\mathrm{P}_{25}-\mathrm{P}_{75} \\
\mathrm{~V} \text { modelling, family routine and demand }\end{array}$ & $2 \cdot 6-4 \cdot 2$ & $2 \cdot 8-4 \cdot 4$ & $2 \cdot 8-4 \cdot 2$ & $2 \cdot 4-4 \cdot 0$ & $2 \cdot 8-4 \cdot 2$ & $2 \cdot 8-4 \cdot 2$ & $2 \cdot 6-4 \cdot 0$ \\
\hline Median§, $\|$ & $4 \cdot 25$ & $3 \cdot 75$ & $4 \cdot 00$ & $3 \cdot 75$ & $4 \cdot 00^{\star \star \star}$ & $4 \cdot 00$ & $4 \cdot 00^{*}$ \\
\hline $\begin{array}{c}\mathrm{P}_{25}-\mathrm{P}_{75} \\
\mathrm{~F} \text { modelling }\end{array}$ & $3 \cdot 75-4 \cdot 75$ & $3 \cdot 0-4 \cdot 24$ & $3 \cdot 5-4 \cdot 5$ & $3 \cdot 0-4 \cdot 25$ & $3 \cdot 25-4 \cdot 5$ & $3 \cdot 25-4 \cdot 5$ & $3 \cdot 25-4 \cdot 5$ \\
\hline Median§, & $4 \cdot 00$ & $4 \cdot 00$ & 3.50 & $3 \cdot 50$ & $4 \cdot 00^{\star \star \star}$ & $4 \cdot 00$ & $4 \cdot 00$ \\
\hline $\begin{array}{l}\mathrm{P}_{25}-\mathrm{P}_{75} \\
\mathrm{FV} \text { snacking practices }\end{array}$ & $3 \cdot 0-4 \cdot 5$ & $3 \cdot 5-4 \cdot 5$ & $3 \cdot 0-4 \cdot 0$ & $3 \cdot 0-4 \cdot 0$ & $3 \cdot 0-4 \cdot 5$ & $3 \cdot 0-4 \cdot 5$ & $3 \cdot 0-4 \cdot 5$ \\
\hline Median§, „I & $3 \cdot 00$ & $3 \cdot 33$ & $3 \cdot 00$ & 3.00 & $3 \cdot 00^{\star \star \star}$ & $3 \cdot 00$ & $3 \cdot 00$ \\
\hline $\begin{array}{l}\mathrm{P}_{25}-\mathrm{P}_{75} \\
\mathrm{FV} \text { allowing }\end{array}$ & $2 \cdot 33-3 \cdot 33$ & $2 \cdot 67-4 \cdot 0$ & $2 \cdot 33-3 \cdot 33$ & $2 \cdot 33-3 \cdot 33$ & $2 \cdot 33-3 \cdot 67$ & $2 \cdot 33-3 \cdot 67$ & $2 \cdot 33-3 \cdot 67$ \\
\hline Median§, ॥ & $4 \cdot 50$ & $5 \cdot 00$ & $5 \cdot 00$ & $5 \cdot 00$ & $5 \cdot 00^{\star \star \star}$ & $5 \cdot 00$ & $5 \cdot 00$ \\
\hline $\mathrm{P}_{25}-\mathrm{P}_{75}$ & $3 \cdot 5-5 \cdot 0$ & $4 \cdot 5-5 \cdot 0$ & $4 \cdot 5-5 \cdot 0$ & $4 \cdot 0-5 \cdot 0$ & $4 \cdot 0-5 \cdot 0$ & $4 \cdot 5-5 \cdot 0$ & $4 \cdot 0-5 \cdot 0$ \\
\hline
\end{tabular}

$\mathrm{P}_{25}-\mathrm{P}_{75}, 25$ th percentile-75th percentile.

Statistical significance of the difference between countries or genders: ${ }^{\star} P<0.05$, ${ }^{\star \star} P<0.01,{ }^{\star \star \star} P<0.001$.

tTested by variance analysis.

$\ddagger \chi^{2}$ test.

§Kruskall-Wallis test (country differences).

॥Mann-Whitney $U$ test (gender differences). 
Table 3 Associations between family-environmental factors and children's daily fruit and vegetable intake, Pro Greens project, 2009

\begin{tabular}{|c|c|c|c|c|}
\hline & OR & $95 \% \mathrm{Cl}$ & $P$ value & $\begin{array}{l}\text { Interactiont, family-environmental factor } \times \\
\text { school lunch policy ( } P \text { value })\end{array}$ \\
\hline \multicolumn{5}{|l|}{ Daily fruit } \\
\hline FV encouragement & $1 \cdot 418$ & $1 \cdot 298,1.548$ & $<0.001$ & $0 \cdot 302$ \\
\hline $\mathrm{V}$ modelling, family routine and demand & 1.689 & $1 \cdot 510,1 \cdot 888$ & $<0.001$ & $0 \cdot 801$ \\
\hline F modelling & $1 \cdot 879$ & $1 \cdot 691,2 \cdot 089$ & $<0.001$ & 0.276 \\
\hline FV snacking practices & $1 \cdot 459$ & $1 \cdot 328,1 \cdot 603$ & $<0.001$ & $0 \cdot 843$ \\
\hline FV allowing & $1 \cdot 117$ & $0.993,1.257$ & 0.064 & 0.387 \\
\hline \multicolumn{5}{|l|}{ Daily salad } \\
\hline FV encouragement & $1 \cdot 408$ & $1 \cdot 108,1 \cdot 788$ & 0.005 & 0.666 \\
\hline V modelling, family routine and demand & $2 \cdot 042$ & $1 \cdot 780,2 \cdot 342$ & $<0.001$ & $0 \cdot 844$ \\
\hline F modelling & $1 \cdot 470$ & $1 \cdot 309,1 \cdot 650$ & $<0.001$ & $0 \cdot 441$ \\
\hline FV snacking practices & $1 \cdot 540$ & $1 \cdot 380,1 \cdot 719$ & $<0.001$ & $0 \cdot 617$ \\
\hline FV allowing & $1 \cdot 342$ & $1 \cdot 158,1 \cdot 554$ & $<0.001$ & $0 \cdot 320$ \\
\hline \multicolumn{5}{|l|}{ Daily raw vegetables } \\
\hline FV encouragement & $1 \cdot 568$ & $1 \cdot 381,1 \cdot 781$ & $<0.001$ & 0.588 \\
\hline $\mathrm{V}$ modelling, family routine and demand & $2 \cdot 314$ & $1 \cdot 944,2 \cdot 755$ & $<0.001$ & 0.035 \\
\hline $\mathrm{F}$ modelling & $1 \cdot 582$ & $1 \cdot 372,1 \cdot 826$ & $<0.001$ & 0.046 \\
\hline FV snacking practices & $1 \cdot 624$ & $1 \cdot 424,1 \cdot 852$ & $<0.001$ & $0 \cdot 258$ \\
\hline FV allowing & $1 \cdot 530$ & $1 \cdot 257,1 \cdot 861$ & $<0.001$ & 0.030 \\
\hline \multicolumn{5}{|l|}{ Daily cooked vegetables } \\
\hline FV encouragement & $1 \cdot 212$ & $1 \cdot 000,1 \cdot 468$ & $0 \cdot 050$ & 0.003 \\
\hline V modelling, family routine and demand & $2 \cdot 212$ & $1 \cdot 655,2 \cdot 957$ & $<0.001$ & $<0.001$ \\
\hline F modelling & $1 \cdot 342$ & $1 \cdot 071,1 \cdot 681$ & $0 \cdot 010$ & 0.972 \\
\hline FV snacking practices & $1 \cdot 214$ & $0.998,1.477$ & 0.052 & 0.761 \\
\hline FV allowing & $1 \cdot 184$ & $0.900,1.558$ & $0 \cdot 227$ & 0.913 \\
\hline
\end{tabular}

Adjusted for children's gender and age, mother's education level, and school lunch policy variable.

Odds ratios derived from multilevel logistic regression analyses, $95 \%$ confidence interval and $P$ values.

tResults from testing interaction terms in multilevel logistic regression analyses. Presented are the significance levels of the interaction terms between familyenvironmental factors and school lunch policy groups (Germany and the Netherlands offer no free school lunches, whereas Finland and Sweden do).

Table 4 Associations between family-environmental factors and daily intake of vegetables by countryt, Pro Greens project, 2009

\begin{tabular}{|c|c|c|c|}
\hline & OR & $95 \% \mathrm{Cl}$ & $P$ value \\
\hline \multicolumn{4}{|l|}{ Raw vegetables } \\
\hline \multicolumn{4}{|c|}{$\mathrm{V}$ modelling, family routine and demand } \\
\hline Germany, the Netherlands & $1 \cdot 878$ & $1 \cdot 378,2 \cdot 559$ & $<0.001$ \\
\hline Finland, Sweden & $2 \cdot 617$ & $2 \cdot 118,3 \cdot 234$ & $<0.001$ \\
\hline \multicolumn{4}{|l|}{ F modelling } \\
\hline Germany, the Netherlands & $2 \cdot 014$ & $1 \cdot 486,2 \cdot 729$ & $<0.001$ \\
\hline Finland, Sweden & $1 \cdot 445$ & $1 \cdot 226,1 \cdot 703$ & $<0.001$ \\
\hline \multicolumn{4}{|l|}{ FV allowing } \\
\hline Germany, the Netherlands & $2 \cdot 266$ & $1 \cdot 464,3 \cdot 508$ & $<0.001$ \\
\hline Finland, Sweden & $1 \cdot 336$ & $1.066,1.648$ & 0.010 \\
\hline \multicolumn{4}{|l|}{ Cooked vegetables } \\
\hline \multicolumn{4}{|l|}{ FV encouragement } \\
\hline Germany, the Netherlands & $1 \cdot 464$ & $1 \cdot 157,1 \cdot 852$ & 0.001 \\
\hline Finland, Sweden & $0 \cdot 728$ & $0.502,1.057$ & 0.095 \\
\hline \multicolumn{4}{|c|}{$\mathrm{V}$ modelling, family routine and demand } \\
\hline Germany, the Netherlands & $3 \cdot 710$ & $2 \cdot 463,5 \cdot 588$ & $<0.001$ \\
\hline Finland, Sweden & 0.964 & $0.609,1.524$ & 0.874 \\
\hline
\end{tabular}

Adjusted for gender and age of child, and mother's education level.

Odds ratios derived from multilevel logistic regression analyses, $95 \%$ confidence intervals and $P$ values.

tStratified analyses were carried out based on the interactions found (see Table 3) between family-environmental factors and whether the country serves a free school lunch (Germany and the Netherlands offer no free school lunches, whereas Finland and Sweden do).

\section{Discussion}

The present study showed that family-environmental factors - perceived modelling, encouragement, parental demand, how much parents allow their children to eat fruits and vegetables, and family routines of eating fruits and vegetables together as school children perceive and report these factors - are associated with daily intake of fruits and vegetables in four countries in Northern and Central Europe. Some evidence supports the hypothesis that family-environmental factors are more strongly related to children's fruit and vegetable intake in those countries which serve no free school lunch.

Daily fruit intake was more common in Germany and the Netherlands than in the Nordic countries. The frequencies of daily fruit intake were in line with data 
from earlier studies conducted in these countries ${ }^{(4,29,37)}$. Children in the Nordic countries more often reported that their daily intake of vegetables included salads, grated vegetables or raw vegetables, whereas a higher proportion of Dutch children reported a daily intake of cooked vegetables. This may stem from differences in food practices between the countries; for example, cooked vegetables are a very common part of dinner in the Netherlands, whereas raw vegetables and salads are common school lunch items in the Nordic countries.

Previous studies have shown that children who receive a compulsory free school lunch that complies with nutritional recommendations consume a substantial part of their daily vegetable intake at this lunch ${ }^{(29,38,39)}$ and have higher

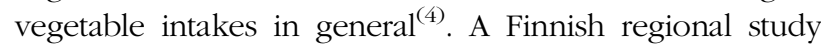
showed that $46 \%$ of children aged 11 years reported eating vegetables daily during the school lunch ${ }^{(38)}$. A recently published study from Finland showed that eating vegetables at school is related to what is served at home. Those children who ate a balanced school lunch (including a main course, vegetables and bread) also ate healthier at home; vegetables were served at every family dinner and fruits were available daily ${ }^{(40)}$. On the other hand, children who must bring their lunch to school may be more likely to bring fruit as a part of their lunch. In the present study, the German and Dutch children had a more frequent daily intake of fruits, probably due to frequent 'fruit breaks' during morning breaks in school ${ }^{(41)}$. In Finland and Sweden, children rarely bring anything to eat to school and fruit breaks in the mornings are rare.

The study showed significant associations between nearly all of the five fruit- and vegetable-specific clusters of family-environmental factors and children's daily fruit and vegetable intake. The present study is rather unique in that it includes a wide range of parenting practices and other family-environmental factors and shows consistent positive associations with intakes. To our knowledge, not all previous studies have shown consistent associations ${ }^{(11,12,14)}$. Overall, the interpretation of these study results and the comparison between studies examining similar relationships in the field of parenting practices and family-environmental factors are challenging due to variation in the terminology and methods used ${ }^{(16,42-44)}$. To our knowledge, at least two studies have reported no association between verbal parental encouragement and fruit and vegetable intake ${ }^{(13,16)}$, whereas the Pro Children study showed associations between maternal or paternal verbal vegetable encouragement and vegetable intake, but no associations between verbal encouragement and fruit intake ${ }^{(11)}$. In contrast to previous studies, the current study used a sum variable consisting of both maternal and paternal encouragement for both fruits and vegetables in the same variable. Nevertheless, nearly all outcomes showed associations, with one exception: no association was found between verbal encouragement and intake of cooked vegetables in the Nordic countries.
The hypothesis predicted that the importance of familyenvironmental factors would be greater in countries where children received no free school lunch; when children received vegetables in the school lunches, the perceived family-environmental factors at home would presumably have less influence. The stratified analyses do not consistently support that hypothesis, however. In the Nordic countries the association between vegetable modelling, family routine and demand and intake of raw vegetables was stronger than in the German and Dutch children. This contrary finding may stem from how children interpreted the questions when examining their parents as models for 'vegetable' eating, how parents demand that their children eat 'vegetables', whether families eat 'vegetables' together and what children used as a reference for the word 'vegetables'. Because eating raw vegetables is quite common in the Nordic countries, the children from Finland and Sweden may have interpreted the questions as referring to 'raw vegetables', whereas the Dutch and German children may have interpreted the question as referring to 'cooked vegetables', since eating cooked vegetables is quite common in Germany and the Netherlands. Nevertheless, some evidence showed that, in line with the hypothesis, family-environmental factors affecting vegetable intakes are more important in Germany and the Netherlands. The stratified analyses revealed, for example, a much stronger association between parents as models for vegetable intake, family routine and demand to eat vegetables, and children's daily intake of cooked vegetables in Germany and the Netherlands than in Finland and Sweden.

The present study has certain limitations. As in all self-report studies, children may have provided socially desirable answers about family-environmental factors or fruit and vegetable intake, which in turn may have influenced the associations. Data were collected regionally in Finland, Germany and Sweden, so the results may not be representative of each country as a whole. Furthermore, the response rate at the school level was low in the Netherlands, thereby possibly reducing the generalisability of the results. However, the intake frequency levels were comparable to those of previous studies $^{(4,37)}$. Despite its limitations, the study has several strengths, including its use of the same questionnaire and study protocol in all four countries. Moreover, the questionnaire used in the current study was previously carefully developed in the Pro Children study in order to assess children's fruit and vegetable intake and personal, social and environmental determinants for the intake $^{(33,34)}$. The food frequency questions, like the questions about determinants, were evaluated for their validity and reliability, and showed satisfactory ability to rank children according to their usual intake ${ }^{(33)}$ as well as satisfactory construct validity and good test-retest reliability ${ }^{(34)}$. In addition, the overall response rate was quite high, especially at the child level, and the sample consisted of data from several European countries. 
The results clearly showed that most family-environmental factors, as clusters, are associated with children's daily fruit and vegetable intake. To date, no other studies about associations between family-environmental factors and fruit and vegetable intake have assessed familyenvironmental factors as different sum variables. Consequently, directly comparing these results with those of previous studies is impossible. However, the Pro Children study, which examined relationships between the same individual family-environmental factors and children's fruit and vegetables intake, showed significant associations ${ }^{(11,26)}$. Exceptions were the associations between parental encouragement and parental allowing, which showed no associations with children's daily fruit intake.

Grouping family-environmental factors as done herein enabled the examination of a more general pattern in family-environmental factors and their associations with fruit and vegetable intakes. This knowledge may prove useful in promoting fruit and vegetable intake among schoolchildren.

\section{Conclusions}

The present study showed that children in four countries in Northern and Central Europe who reported more familyenvironmental factors that promoted fruit and vegetable intake had a more frequent intake of both fruits and vegetables. Furthermore, family-environmental factors were somewhat more strongly associated with children's vegetable intakes in those countries which served no free school lunch. Still, in practical health promotion, the advice to policy makers is to provide healthy school meals to all children. Public health nutritionists should take into consideration family-environmental factors regarding fruits and vegetables, regardless of whether free school lunches are provided, and include parents in nutritional interventions.

\section{Acknowledgements}

Sources of funding: The Pro Greens project has been made possible with the financial support of the Programme of Community Action in the Field of Public Health 2003-2008 of the European Commission. Conflicts of interest: All authors have reviewed and agreed to the content of the revised manuscript and the authors have no competing interests. Authors' contributions: C.R. designed the study, carried out the literature review, analysed the data, interpreted the analysis and results, and drafted the manuscript. E.R. designed the study, interpreted the analysis and results, and commented on the draft of the manuscript. J.B. designed the study, interpreted the analysis and results, and commented on the draft of the manuscript. I.B. provided data about German circumstances and commented actively on the draft of the manuscript. B.E. provided data about Swedish circumstances and commented actively on the draft of the manuscript. A.Y. was responsible for the Pro Greens project, interpreted the results and commented on the draft of the manuscript. S.J.t.V. played an active role in the literature review, analysis of the data, interpreting the analysis and results, and commenting on the draft of the manuscript. All authors have read and approved the final manuscript. Acknowledgements: The authors thank the participating children, their parents, the schools and all the staff who have worked on the Pro Greens project.

\section{References}

1. Hu FB (2003) Plant-based foods and prevention of cardiovascular disease: an overview. Am J Clin Nutr 78, 3 Suppl., 544S-551S.

2. Joshipura KJ, Ascherio A, Manson JE et al. (1999) Fruit and vegetable intake in relation to risk of ischemic stroke. JAMA 282, 1233-1239.

3. Paolini M, Sapone A, Canistro D et al. (2003) Diet and risk of cancer. Lancet 361, 257-258.

4. Yngve A, Wolf A, Poortvliet E et al. (2005) Fruit and vegetable intake in a sample of 11-year-old children in 9 European countries: The Pro Children Cross-sectional Survey. Ann Nutr Metab 49, 236-245.

5. Mikkila V, Rasanen L, Raitakari OT et al. (2004) Longitudinal changes in diet from childhood into adulthood with respect to risk of cardiovascular diseases: the Cardiovascular Risk in Young Finns Study. Eur J Clin Nutr 58, 1038-1045.

6. te Velde SJ, Twisk JW \& Brug J (2007) Tracking of fruit and vegetable consumption from adolescence into adulthood and its longitudinal association with overweight. Br J Nutr 98, 431-438.

7. Brug J, te Velde SJ, Chinapaw MJ et al. (2010) Evidencebased development of school-based and family-involved prevention of overweight across Europe: the ENERGYproject's design and conceptual framework. BMC Public Health 10, 276.

8. Davison KK \& Birch LL (2001) Childhood overweight: a contextual model and recommendations for future research. Obes Rev 2, 159-171.

9. Darling N \& Steinberg L (1993) Parenting styles as a context: an integrative model. Psychol Bull 113, 487-496.

10. Bere E \& Klepp KI (2004) Correlates of fruit and vegetable intake among Norwegian schoolchildren: parental and self-reports. Public Health Nutr 7, 991-998.

11. De Bourdeaudhuij I, te Velde S, Brug J et al. (2008) Personal, social and environmental predictors of daily fruit and vegetable intake in 11-year-old children in nine European countries. Eur J Clin Nutr 62, 834-841.

12. Haerens L, Craeynest M, Deforche B et al. (2008) The contribution of psychosocial and home environmental factors in explaining eating behaviours in adolescents. Eur J Clin Nutr 62, 51-59.

13. Vereecken C, Legiest E, De Bourdeaudhuij I et al. (2009) Associations between general parenting styles and specific food-related parenting practices and children's food consumption. Am J Health Promot 23, 233-240.

14. Young EM, Fors SW \& Hayes DM (2004) Associations between perceived parent behaviors and middle school student fruit and vegetable consumption. J Nutr Educ Behav 36, 2-8.

15. Vereecken CA, Van Damme W \& Maes L (2005) Measuring attitudes, self-efficacy, and social and environmental influences on fruit and vegetable consumption of 11- and 
12-year-old children: reliability and validity. J Am Diet Assoc 105, 257-261.

16. Monge-Rojas R, Smith-Castro V, Colon-Ramos U et al. (2010) Parental feeding styles and adolescents' healthy eating habits. Structure and correlates of a Costa Rican questionnaire. Appetite 55, 253-262.

17. Bauer KW, Neumark-Sztainer D, Fulkerson JA et al. (2011) Familial correlates of adolescent girls' physical activity, television use, dietary intake, weight, and body composition. Int J Behav Nutr Phys Act 8, 25.

18. Beydoun MA \& Wang Y (2009) Parent-child dietary intake resemblance in the United States: evidence from a large representative survey. Soc Sci Med 68, 2137-2144.

19. Bjelland M, Lien N, Grydeland $M$ et al. (2011) Intakes and perceived home availability of sugar-sweetened beverages, fruit and vegetables as reported by mothers, fathers and adolescents in the HEIA (HEalth In Adolescents) study. Public Health Nutr (Epublication ahead of print version).

20. Elfhag K, Tholin S \& Rasmussen F (2008) Consumption of fruit, vegetables, sweets and soft drinks are associated with psychological dimensions of eating behaviour in parents and their 12-year-old children. Public Health Nutr 11, 914-923.

21. Kristjansdottir AG, De Bourdeaudhuij I, Klepp KI et al. (2009) Children's and parents' perceptions of the determinants of children's fruit and vegetable intake in a low-intake population. Public Health Nutr 12, 1224-1233.

22. Burgess-Champoux TL, Larson N, Neumark-Sztainer D et al. (2009) Are family meal patterns associated with overall diet quality during the transition from early to middle adolescence? J Nutr Educ Behav 41, 79-86.

23. Gillman MW, Rifas-Shiman SL, Frazier AL et al. (2000) Family dinner and diet quality among older children and adolescents. Arch Fam Med 9, 235-240.

24. Larson NI, Neumark-Sztainer D, Hannan PJ et al. (2007) Family meals during adolescence are associated with higher diet quality and healthful meal patterns during young adulthood. J Am Diet Assoc 107, 1502-1510.

25. Videon TM \& Manning CK (2003) Influences on adolescent eating patterns: the importance of family meals. $J$ Adolesc Health 32, 365-373.

26. Brug J, Tak NI, te Velde SJ et al. (2008) Taste preferences, liking and other factors related to fruit and vegetable intakes among schoolchildren: results from observational studies. Br J Nutr 99, Suppl. 1, S7-S14.

27. National Food Agency (2007) Bra mat i skolan (Advice for good food in the school). http://www.slv.se/ upload/dokument/mat/mat_skola/Bra_mat_i_skolan_2007.pdf (accessed December 2012).

28. National Nutrition Council (2008) Kouluruokailusuositus (Dietary Guidelines for School Meals), 1st ed. Helsinki: Savion Kirjapaino Oy.

29. Hoppu U, Lehtisalo J, Tapanainen H et al. (2010) Dietary habits and nutrient intake of Finnish adolescents. Public Health Nutr 13, 965-972.

30. Fischer C, Brug J, Tak NI et al. (2011) Differences in fruit and vegetable intake and their determinants among 11-year-old schoolchildren between 2003 and 2009. Int J Behav Nutr Phys Act 8, 141.

31. Brug J, Yngve A \& Klepp KI (2005) The Pro Children study: conceptualization, baseline results and intervention development of a European effort to promote fruit and vegetable consumption in schoolchildren. Ann Nutr Metab 49, 209-211.

32. Klepp KI, Perez-Rodrigo C, De Bourdeaudhuij I et al. (2005) Promoting fruit and vegetable consumption among European schoolchildren: rationale, conceptualization and design of the pro children project. Ann Nutr Metab 49, 212-220.

33. Haraldsdottir J, Thorsdottir I, de Almeida MD et al. (2005) Validity and reproducibility of a precoded questionnaire to assess fruit and vegetable intake in European 11- to 12-year-old schoolchildren. Ann Nutr Metab 49, 221-227.

34. De Bourdeaudhuij I, Klepp KI, Due P et al. (2005) Reliability and validity of a questionnaire to measure personal, social and environmental correlates of fruit and vegetable intake in 10-11-year-old children in five European countries. Public Health Nutr 8, 189-200.

35. Twisk JW (2006) Applied Multilevel Analysis: A Practical Guide, 1st ed. Cambridge: Cambridge University Press.

36. Rasbash J, Charlton C, Browne WJ et al. (2009) MLwiN version 2.1. Bristol: Centre for Multilevel Modelling, University of Bristol.

37. Wind M, de Bourdeaudhuij I, te Velde SJ et al. (2006) Correlates of fruit and vegetable consumption among 11-year-old Belgian-Flemish and Dutch schoolchildren. J Nutr Educ Behav 38, 211-221.

38. Haapalahti M, Mykkanen H, Tikkanen S et al. (2003) Meal patterns and food use in 10- to 11-year-old Finnish children. Public Health Nutr 6, 365-370.

39. Robinson-O'Brien R, Burgess-Champoux T, Haines J et al. (2010) Associations between school meals offered through the National School Lunch Program and the School Breakfast Program and fruit and vegetable intake among ethnically diverse, low-income children. J Sch Health 80, 487-492.

40. Tilles-Tirkkonen T, Pentikainen S, Lappi J et al. (2011) The quality of school lunch consumed reflects overall eating patterns in 11-16-year-old schoolchildren in Finland. Public Health Nutr (Epublication ahead of print version).

41. Tak NI, Te Velde SJ, Singh AS et al. (2010) The effects of a fruit and vegetable promotion intervention on unhealthy snacks during mid-morning school breaks: results of the Dutch Schoolgruiten Project. J Hum Nutr Diet 23, 609-615.

42. Dave JM, Evans AE, Condrasky MD et al. (2012) Parentreported social support for child's fruit and vegetable intake: validity of measures. J Nutr Educ Behav 44, 132-139.

43. Rasmussen M, Krolner R, Klepp KI et al. (2006) Determinants of fruit and vegetable consumption among children and adolescents: a review of the literature. Part I: quantitative studies. Int J Behav Nutr Phys Act 3, 22.

44. Robinson-O'Brien R, Neumark-Sztainer D, Hannan PJ et al. (2009) Fruits and vegetables at home: child and parent perceptions. J Nutr Educ Behav 41, 360-364. 